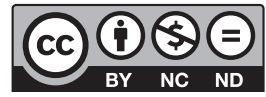

Estudos Teológicos foi licenciado com uma Licença Creative Commons Atribuição - NãoComercial - SemDerivados 3.0 Não Adaptada

http://dx.doi.org/10.22351/et.v60i1.3920

\title{
DERECHOS HUMANOS Y LIBERTAD RELIGIOSA: RESISTENCIAS AL CRISTOFASCISMO EN BRASIL ${ }^{1}$ \\ Human rights and religious freedom: resistances to Christofascism in Brazil
}

\section{Claudete Beise Ulrich ${ }^{2}$ Marga Janete Ströher ${ }^{3}$ Nivia Ivette Núñez de la $\mathrm{Paz}^{4}$}

Resumen: El presente artículo reflexiona sobre la importancia del respeto a las libertades individuales, entre estas el derecho de tener o no tener una religión. La religión, especialmente la cristiana, ha sido utilizada para justificar actitudes y acciones cristofascistas, apoyadas en un proceso de neo-Colonialidad y de necropolítica. La problemática de este trabajo se insiere en la pregunta de cómo la religión, un derecho humano personal y privado, ha sido usado por medio de grupos políticos cristianos, firmándose en un poder fundamentado en la intolerancia religiosa y la muerte, especialmente, de los pueblos afrobrasileños e indígenas. A partir de la Declaración Universal de los Derechos Humanos y de la Constitución brasileña se afirma la diversidad religiosa, la laicidad, la importancia de las políticas públicas en la superación de discursos y acciones coloniales y cristofascistas que configuran una necropolítica - la política de la muerte. Las reflexiones están fundamentadas en la Declaración Universal de los Derechos Humanos, Constitución Federal de Brasil, Boris Alfonso Ramírez Guzmán, Aníbal Quijano, Achille Mbembe, Rosane Borges, Roseli Fischmann, Flávia Piovesan, Dorothee Sölle, Roberto Arriada Lorea, Daniel Sarmento, Boaventura de Sousa Santos, Maria Paula Meneses.

Palabras Claves: Derechos humanos. Necropolítica. Cristofascismo. Diversidad religiosa. Políticas públicas.

Abstract: This article reflects on the importance of respect for individual freedoms, including the right to have or not have a religion. Religion, especially the Christian has been used to justify christofascists attitudes and actions, supported by a process of neo-colonialism and necropolitics. The problem of this work is part of the question of how religion, a personal and private human right, has been used through Christian

1 O artigo foi recebido em 03 de março de 2020 e aprovado em 13 de abril de 2020 com base nas avaliações dos pareceristas ad hoc.

2 Doutora em Teologia. Faculdade UNIDA de Vitória. E-mail: claudetebeiseulrich@hotmail.com

3 Doutora em Teologia. SINAL - Faculdade de Ciências Humanas e Sociais. E-mail: margastroher@gmail.com

4 Doutora em Teologia. Universidad Internacional Iberoamericana - UNINI e da Universidad Europea del Atlantico - UNEATLANTICO. E-mail: nnpaz@hotmail.com 
political groups, establishing itself as a power based on religious intolerance and death, especially of Afro-Brazilians and indigenous peoples. From the Universal Declaration of Human Rights and the Brazilian Constitution, religious diversity, secularity, importance of public policies in overcoming colonial and christofascists discourses and actions that configure a necropolitics - the politics of death. The reflections are based in the Universal Declaration of Human Rights, Constitución Federal de Brasil, Boris Alfonso Ramírez Guzmán, Aníbal Quijano, Achille Mbembe, Rosane Borges, Roseli Fischmann, Flávia Piovesan, Dorothee Sölle, Roberto Arriada Lorea, Daniel Sarmento, Boaventura de Sousa Santos, Maria Paula Meneses.

Keywords: Human rights. Necropolitics. Christofascism/Christofaschismus. Religious diversity. Public policies.

\section{Introducción}

Los llamados derechos humanos forman parte de una construcción histórica y son resultado de muchas luchas y conquistas, expresados por primera vez en su forma actual en la Declaración Universal de los Derechos Humanos (DUDH) de $1948^{5}$. Esa declaración es fruto de un pacto de consolidación en el ámbito de la Organización de las Naciones Unidas y, hoy, asumida por los países democráticos como una referencia de ética y de valores socialmente deseables. Es un instrumento, un código de conducta internacional que expresa los "derechos fundamentales de la persona humana", o sea, el mínimo necesario para vivir con dignidad. Derechos humanos son, por lo tanto, los derechos considerados fundamentales a la persona humana, el conjunto de derechos y garantías del ser humano que tiene por finalidad básica el respeto a su dignidad, por medio de su protección contra el abuso de poder del Estado y el establecimiento de condiciones mínimas de vida y desarrollo de la personalidad humana.

Los principios presentes en la Declaración Universal de los Derechos Humanos se sitúan en la confluencia democrática entre los derechos y libertades individuales y los deberes para con la comunidad en que se vive. Y todos los seres humanos, independientemente de su edad, sexo, raza, etnia, opción en relación a la religión, ideología, orientación sexual, o cualquier característica personal o social, poseen derechos humanos. Cualquier tipo de discriminación que mantenga o promueva desigualdad consiste en una violación de esos derechos.

Los derechos humanos son considerados universales, históricos, inalienables, imprescriptibles, irrenunciables, indivisibles e interdependientes y, por tanto, de todas las personas y, aún más, extensivos a los derechos ambientales. A pesar de su internacionalización, los derechos humanos comienzan a asentarse en Brasil a partir del proceso de redemocratización del país y sus referenciales tuvieron una gran influencia

5 DECLARAÇÃO UNIVERSAL DOS DIREITOS HUMANOS. Disponível em: < https://www.unicef.org/ brazil/pt/resources_10133.htm>. Acesso em: 05 fev. 2020. 
en el proceso constituyente, que culminó con la proclamación de la Constitución Ciudadana de $1988^{6}$.

La adopción de tales medidas fortalece la democracia participativa ${ }^{7}$, en la cual el Estado actúa como instancia de promoción y defensa de los Derechos Humanos y la sociedad civil como agente activo de su implementación. Con todo, la garantía de los derechos fundamentales es un proceso complejo que camina al lado de resistencias en su afirmación y respeto. Hay muchas resistencias a esta comprensión amplia de los derechos humanos, especialmente entre personas que piensan y defienden que estos deben ser restringidos y que hay personas que no merecían la garantía de sus derechos humanos.

Intentando entender lo que sucede en Brasil contemporáneo preguntamos: ¿Cuáles referenciales hermenéuticos podemos utilizar para hacer una lectura de lo que ocurre en Brasil desde el golpe de 2016 y 2018 (con una elección pautada por fake news)? Entendemos que apenas una hermenéutica insurgente es capaz de ayudar en la lectura e interpretación de este contexto y responder a las preguntas que cotidianamente somos obligadas a realizar frente a este cuadro de fundamentalismo religioso y político exacerbado que se establece en el contexto en que vivimos. Al mismo tiempo en que hacemos la lectura, en tanto sujetos interpretativos, también formamos parte de los hechos y nos rebelamos y buscamos crear mecanismos de resistencia y sobrevivencia. Es la rebeldía que nos mantiene conectadas con los valores de la democracia ciudadana, de la justicia y de los derechos humanos. Porque respeto no existe, política pública no existe, seguridad social no existe, cultura no existe, democracia no existe. Todo está siendo destruido, aniquilado, hay una implantación de una deshumanización generalizada, protocolada por un cristianismo que afirma la muerte de las diferencias. En este sentido, el presente artículo reflexiona sobre la importancia del respeto a las libertades individuales, entre ellas el derecho a tener o no tener una religión, y como ellas están siendo amenazadas a partir de la nueva forma de colonización, de la ideología cristofascista, de la necropolítica. Se busca imponer un cristianismo fundamentalista, que no respeta las diferencias y la pluralidad como posibilidad de superación de los embates históricos que estamos viviendo.

\section{Derecho a la libertad religiosa}

Hace casi 72 años, el 10 de diciembre de 1948, fue proclamada y adoptada la Declaración de los Derechos Humanos por la Asamblea General de las Naciones Unidas (resolución 217 A III). Podríamos preguntar: ¿Que son los derechos humanos? Son los derechos que las personas poseen, a priori, por ser humanas, garantizando su dignidad.

6 BRASIL. Constituição da República Federativa do Brasil. 1988. [recurso eletrônico]. Brasília: Supremo Tribunal Federal, Secretaria de Documentação, 2019. Disponível em: <https://www.stf.jus.br/arquivo/ cms/legislacaoConstituicao/anexo/CF.pdf>. Acesso em: 05 fev. 2020.

7 STRÖHER, Marga Janete. Laicidade e democracia na interface com a laicidade e os direitos humanos. Monografia (Especialização em Gestão de Políticas Públicas em Direitos Humanos) - Escola Nacional de Administração Pública, Brasília, 2014. p. 33-35. 
La propia declaración ya anuncia que es declaración universal, válida para todas las personas y todos los pueblos. Derechos humanos son definidos por un conjunto de derechos civiles, políticos, sociales, económicos, culturales y ambientales, sean ellos individuales, colectivos, transindividuales o difusos. En la Declaración se encuentra definido cuales los derechos universales, inviolables e inalienables de toda persona humana. Importante dejar claro que la declaración de los Derechos Humanos es resultado de un proceso histórico terrible, la segunda guerra mundial, donde muchos derechos fueron violados.

La garantía de los derechos humanos pasa por la garantía de los miembros de un grupo, de una sociedad, de un país. La afirmación de que los derechos sean inherentes a cada persona no garantiza la existencia de esos derechos, o su reconocimiento o concretización. El derecho a la igualdad aún es una lucha de las mujeres y de las personas negras e indígenas. Este derecho es asegurado, pero en el cotidiano aún existe mucha desigualdad social, machismo, racismo, violencia de género, intolerancia religiosa. El derecho a tener una religión aún hoy no es una garantía. En Brasil, especialmente, las religiones indígenas y afrobrasileñas, cotidianamente sufren ataques, prejuicios, destrucciones e, inclusive, muerte. Aquello que sale del padrón oficial es perseguido y necesita ser destruido.

El primer artículo de la Declaración Universal de los Derechos Humanos afirma:

\section{Artículo 1}

Todos los seres humanos nacen libres e iguales en dignidad e derechos. Son dotados de razón y consciencia y deben actuar em relación unos a los otros con espíritu de fraternidad. ${ }^{8}$

Desde el inicio la declaración afirma la libertad y la igualdad en dignidad de todas las personas y la relación entre las personas, comunidades y pueblos necesita darse en un clima de fraternidad. Lynn Hunt afirma que autonomía y empatía son construcciones culturales, fundamentales para el ejercicio de la libertad, de la igualdad, de la dignidad y de la fraternidad:

La autonomía y la empatía son prácticas culturales y no apenas ideas, y por tanto son incorporadas de forma bastante literal, esto es, tienen dimensiones tanto físicas como emocionales. La autonomía individual depende de una percepción creciente de la separación y del carácter sagrado de los cuerpos humanos: su cuerpo es suyo, y mi cuerpo es mío, y debemos ambos respetar las fronteras entre los cuerpos uno del otro. Ya la empatía depende del reconocimiento de que los otros sienten y piensan como hacemos, de que nuestros sentimientos interiores son semejantes de un modo esencial. ${ }^{9}$

8 DECLARAÇÃO UNIVERSAL DOS DIREITOS HUMANOS. Disponível em: < https://www.unicef.org/ brazil/pt/resources_10133.htm>. Acesso em: 05 fev. 2020.

9 HUNT, Lynn. A Invenção dos Direitos Humanos: uma história. São Paulo: Companhia das Letras, 2009. p. 27. 
Los seres humanos necesitan aprender de autonomía, esto es, pensar por si mismos, sin la tutela de un otro, en respeto a sí mismo y a otro/a. La empatía tiene que ver con la percepción de que el otro sufre, siente así como cada uno sufre y siente. La empatía conduce hacia la solidaridad. En este sentido, es necesario aprender empatía en relación a la religión de los diversos grupos humanos. Los derechos humanos afirman el reconocimiento de la dignidad humana. La dignidad humana no puede ser violada y cada ser humano tiene el derecho de tener o no tener una religión. Cada ser humano necesita ser respetado, independientemente de su clase social, raza/etnia, género, orientación sexual, etc.

La libertad religiosa es uno de los derechos fundamentales de la humanidad, como afirma la Declaración Universal de los Derechos Humanos, en los artículos 2 y 18.

\begin{abstract}
Artículo 2
Todo ser humano tiene capacidad para gozar los derechos y las libertades establecidas en esta Declaración, sin distinción de cualquier especie, sea de raza, color, sexo, lengua, religión, opinión política o de otra naturaleza, origen nacional o social, riqueza, nacimiento o cualquier otra condición.
\end{abstract}

Artículo 18

Todo ser humano tiene derecho a la libertad de pensamiento, conciencia y religión, ese derecho incluye la libertad de cambiar de religión o creencia y la libertad de manifestar esa religión o creencia por la enseñanza, por la práctica, por el culto en público o en particular. ${ }^{10}$

El artículo 18 evidencia que cada ser humano tiene derecho a la libertad de pensamiento, conciencia y de religión. Esto también significa que el cambio de religión o creencia constituye un derecho. La persona tiene también la libertad de expresar aquello que cree o no cree, su religión, a través de la enseñanza, de la práctica, del culto y este puede ser público o particular. En el artículo 18 se percibe la articulación de las palabras: pensamiento, consciencia y religión.

Interesante como las palabras "pensamiento", “conciencia” y "religión” están vinculadas al estado de ser libre. La libertad de pensar/saber, ser/actuar y creer, desde que no perjudique el otro en la relación, es fundamental para el desarrollo no solo del individuo, con todas sus particularidades, mas, sobre todo, para el ciudadano que se sitúa en los espacios públicos de forma crítica y constructiva. ${ }^{11}$

Por tanto, la libertad de pensar, preguntar, conocer, vivir, actuar es fundamental para el desarrollo individual como para la convivencia ciudadana, en el espacio público, en una sociedad democrática. La Constitución Federativa de Brasil también consagra en su artículo $5^{\circ}$ :

${ }^{10}$ DECLARAÇÃO UNIVERSAL DOS DIREITOS HUMANOS. Disponível em: < https://www.unicef.org/ brazil/pt/resources_10133.htm>. Acesso em: 05 fev. 2020.

${ }^{11}$ CUNHA, Carlos Alberto Motta. Teologia, Direitos Humanos e Pensamento Decolonial. Horizonte, v. 15, n. 47, p. 697-718, jul./set. 2017. p. 698. Disponível em: <http://periodicos.pucminas.br/index.php/ horizonte/article/view/P.2175-5841.2017v15n47p697>. Acesso em: 05 fev. 2020. 
Inciso VI - Es inviolable la libertad de consciencia y de creencia, siendo asegurado el libre ejercicio de los cultos religiosos y garantizada, en la forma de la ley, la protección a los locales de culto y a sus liturgias. ${ }^{12}$

A pesar de estar garantizada la libertad de religión y de culto existe en Brasil mucha intolerancia religiosa. La intolerancia compromete la dignidad de la persona humana. En Brasil la intolerancia está ligada, especialmente, al racismo. Son las religiones de matriz afro-brasileñas que sufren más persecución. El Estado brasileño es laico, o sea, no tiene religión. Tiene sí, el deber de garantizar la libertad religiosa. En el momento en que una persona es humillada, discriminada, agredida debido a su creencia, ella tiene sus derechos constitucionales y sus derechos humanos violados, o sea, es también una víctima de un crimen - y el Código Penal brasileño prevé punición para los criminosos. En Brasil la intolerancia religiosa es considerada crimen, previsto en el artículo 20 de la Ley $N^{0}$ 7.716/89. Por tanto, practicar, inducir o incitar a la discriminación y prejuicio en razón de religión es un hecho que puede llevar al infractor a cumplir pena de reclusión de uno a tres años, además de multa.

La práctica de una religión es un asunto personal y privado. Lo que corresponde a cada cual de nosotros es respetar la práctica religiosa de cada persona. El Estado y sus gobiernos necesitan garantizar la libertad individual en el derecho de escoger su religión.

\section{Brasil y la nueva colonialidad}

El concepto de colonialidad es definido como el patrón colonial de poder, en la perspectiva de la existencia/ser y del conocimiento/saber. Colonialidad es más que colonización (física, material, territorial, mercantilista) porque alcanza el ser, el tener, el saber y el poder. ${ }^{13}$ Según Boris Guzman, hay una Colonialidad del ser "como ejercicio de inferiorizar, subalternizar y deshumanización racial en la modernidad, la falta de humanidad en los sujetos colonizados que los separa de la modernidad, de la razón y de las facultades cognitivas"14.

Aníbal Quijano, a partir del concepto de colonialidad, muestra la relación indisociable con la clasificación social, la articulación entre política y cuestiones geo-culturales, la distribución mundial del trabajo, las relaciones culturales e intersubjetivas, la dominación y la explotación ${ }^{15}$. Esa colonialidad es el origen y genera todo tipo de prejuicio, discriminación e intolerancia.

12 BRASIL. Constituição da República Federativa do Brasil. 1988. [recurso eletrônico]. Brasília: Supremo Tribunal Federal, Secretaria de Documentação, 2019. p. 17. Disponível em: <https://www.stf.jus.br/ arquivo/cms/legislacaoConstituicao/anexo/CF.pdf>. Acesso em: 05 fev. 2020.

13 STRÖHER, 2014, p. 27-33.

${ }^{14}$ GUZMÁN, Boris Alfonso Ramírez. Colonialidade, interculturalidade e educação: desdobramento na relação do povo Mapuche e o Estado do Chile. Dissertação (Mestrado em Educação) - Programa de Pós-Graduação em Educação da Universidade Federal de Santa Catarina, Florianópolis, 2011. p. 46. Disponível em: <https:// repositorio.ufsc.br/bitstream/handle/123456789/94931/300059.pdf?sequence=1>. Acesso em: 27 jan. 2020.

15 QUIJANO, Aníbal. Colonialidade do poder e classificação social. In: SANTOS, Boaventura de Sousa; MENESES, Maria Paula (Orgs.). Epistemologias do Sul. São Paulo: Cortez, 2010. p. 113. 
El contexto brasileño está marcado, desde el golpe de 2016, después de un corto espacio de un gobierno con características populares y de implementación de políticas públicas más inclusivas a partir de 2003, por esa colonialidad de poder, justificada por grupos evangélicos de línea neopentecosta ${ }^{16}$. Los ataques a las religiones diferentes (especialmente afrobrasileñas), el crecimiento generalizado de la violencia, la deteriorización de las relaciones por la intolerancia y por los discursos de odio, el aumento del femicidio, el asesinato de jóvenes negros y de la población LGBT, la eliminación de testigos de crímenes de políticos, el asesinato sistemático de líderes indígenas por el latifundio colonizador, el no reconocimiento de las comunidades de quilombos, la persecución y muerte de líderes de movimientos sociales y ambientales y de defensores de derechos humanos, la precarización del trabajo, el fin de la seguridad social (salud, asistencia y previdencia social), la militarización de las instituciones, el empobrecimiento de la población y el aumento drástico del hambre y de la población en situación de calle, el fin o la reducción de programas sociales, la privatización de empresas públicas, la amenaza a la educación pública, los ataques a la cultura son consecuencia de esa "nueva" colonialidad.

Brasil está siendo gobernado por grupos peligrosos ligados a las milicias y bajo el broquel de grupos religiosos fundamentalistas - aliados del latifundio, del agronegocio y de las mineradoras - que comprometen no apenas la laicidad del Estado, como de todas las instituciones democráticas y las políticas públicas en nombre de valores y discursos moralistas y que legitiman la implantación del neoliberalismo en su peor fase.

Todo lo que asistimos es el desmantelamiento de la Nación por la asociación del Estado con lo que hay de más cruel del neoliberalismo en función del capital y mercado financiero. Todo es destrucción legitimada simbólica y materialmente por el fundamentalismo religioso. Un fundamentalismo que adviene de un ala del neopentecostalismo que se desarrolló en Brasil en las últimas cuatro décadas ${ }^{17}$. Las iglesias neopentecostales se organizan en formato de empresas capitalistas, esto es, hacen promociones de la fe, en este caso, cristiana. Todos los días tienen cultos y cada día hay

${ }^{16}$ Paul Freston utilizó la metáfora de las olas marinas para tipificar el pentecostalismo en Brasil. En cada ola el pentecostalismo viene con algún cambio. Los neopentecostales pertenecen a la tercera ola do pentecostalismo. Ellos utilizan los medios electrónicos, la televisión, entre otros. Se expandieron a partir de la década del 70. Uno de los mayores representantes de esta ola es el obispo Edir Macedo. El énfasis del discurso religioso está en la Teología de la Prosperidad. A partir de esta ola, hay más evangélicos participando de partidos políticos, formando, en Brasil, "la bancada evangélica", que se sitúa en gran medida, contra las agendas progresistas de los derechos humanos. Ver FRESTON, Paul. Breve histórico do pentecostalismo brasileiro. In: ANTONIAZZI, Alberto et al. Nem anjos nem demônios: interpretações sociológicas do pentecostalismo. Petrópolis: Vozes, 1994. p. 70.

17 MARIANO, Ricardo. Neopentecostais: Sociologia do novo pentecostalismo no Brasil. 5. ed. São Paulo: Loyola, 2005. p. 7. De acuerdo con el autor, hasta dos décadas atrás seria inconcebible que un creyente pentecostal fuera al templo para, en fervorosas corrientes de oración semana atrás de semanas, y por medio de regateos cósmicos - teniendo la iglesia como intermediaria y caja económica de transacciones - desafiar a Dios con el fin de prosperar materialmente. Igual de inimaginable seria convidar, además de clientes fluctuantes, creyentes de denominaciones de la concurrencia para frecuentar cultos en los cuales ellos, literalmente, podrían protegerse de las investidas del diablo y liberarse de la posesión demoníaca. [...] 
ofertas de solución para algún problema. Este fundamentalismo, unido a las milicias, se instaló en el poder máximo de la República y transforma el pueblo en rehenes paralizados por la inercia y la inexistencia de nuevas utopías. Las personas que participan de estas comunidades religiosas siguen ciegamente, sin criticidad, el liderazgo religioso.

Pensamos que el concepto de necropolítica - la política de la muerte - desarrollado por el científico político e historiador camaronéense Achille Mbembe es el que mejor define esa realidad. La necropolítica es la política de la muerte adoptada por el Estado. El cuestiona los límites de la soberanía cuando el Estado escoge quien debe vivir y quien debe morir. Es el Estado de excepción, el estado de sitio, el estado de terror, del terrorismo (como fue el nacismo) ${ }^{18}$.

El autor entiende que la expresión máxima de soberanía reside, en gran medida, en el poder y en la capacidad de dictar quien puede vivir y quien debe morir. "Por eso, matar o dejar vivir constituyen los límites de la soberanía, sus atributos fundamentales" 19 . Y trae una percepción del racismo a partir del concepto de biopoder de Michael Foucault - que funciona por la división entre las personas que deben vivir y las que deben morir - y la política de la raza de Hannah Arendt que está relacionada con la política de la muerte. "Ese control presupone la distribución de la especie humana en grupos, la subdivisión de la población en subgrupos y el establecimiento de una cesura biológica entre unos y otros" ${ }^{20}$.

Rosane Borges realiza un análisis acertada en relación a lo que ocurre en Brasil, sobre el concepto de necropolítica adoptado por el presidente Bolsonaro:

El presidente habla em ser soberano, que nadie puede mandar en la amazonia, pero antes de él tener ese discurso él fue, desde una perspectiva, colonizado por los Estados Unidos. Brasil está escogiendo ser colonia. La colonia tenía una expropiación del cuerpo, el cuerpo que era esclavizado, un cuerpo moneda, objeto. Lo que permanece es el cuerpo que es matable. No es más estatuto jurídico del esclavizado, más digamos que esa esclavización se da de otras formas. A partir de imaginarios, de políticas que definen lo normal y lo desviante, el bien y el mal, lo bello y lo feo. La gente va viendo esas jerarquías se manteniendo, el fantasma de la esclavitud y de la colonia es una presencia muy fuerte. Inclusive orienta políticas contemporáneas ${ }^{21}$.

$\mathrm{Y}$ en este escenario ha aumentado la intolerancia religiosa, especialmente a las religiones de matriz africana e indígena. $\mathrm{O}$ sea, las cuestiones de intolerancia religiosas enfrentadas en el país están ligadas al racismo y a la comprensión equivocada de la laicidad, en que indios y negros no serían la mayoría en esta llamada democracia y,

${ }_{18}$ MBEMBE, Achille. Necropolítica. Arte \& Ensaios, Revista do PPGAV/EBA/UFRJ, n. 32, p. 127-128, dez. 2016. Disponível em: <https://www.procomum.org/wp-content/uploads/2019/04/necropolitica.pdf>. Acesso em: 18 fev. 2020

${ }_{19}$ MBEMBE, 2016, p. 123.

${ }^{20}$ MBEMBE, 2016, p. 128.

${ }^{21}$ BORGES, Rosane. In: FERRARI, Mariana. O que é necropolítica. E como se aplica à segurança pública no Brasil. Entrevista com Rosane Borges. Ponte, 25.09.2019. Disponível em: <https://ponte.org/o-quee-necropolitica-e-como-se-aplica-a-seguranca-publica-no-brasil/>. Acesso em: 17 fev. 2020. 
por tanto, deben someterse a las injerencias y al metadiscurso normativo y ni recibir cualquier privilegio de la religión de las mayorías.

Todos los avances sociales conquistados en los últimos años se convierten relativizados en el escenario actual cuando el "dios - mercado" pasa a regir las normas y los valores sociales y culturales. El mercado toma la religión como rehén y la instrumentaliza por medio de sus símbolos, rituales, iconografías y discursos mediáticos performativos para implantar un gobierno o un sistema político que esté aliado al capitalismo neoliberal. $\mathrm{O}$ sea, el fundamentalismo religioso que sustenta un fundamentalismo político, y este se utiliza del discurso religioso para alimentar el mercado $\mathrm{y}$ destruir todo lo que se opone a este proyecto de muerte.

\section{Libertad religiosa y laicidad}

Brasil es Estado laico desde la primera República. Todavía en el gobierno provisorio, por el Decreto 119-A, de 17 de enero de 1890, se instauró la separación entre la iglesia y el Estado. Este Decreto prohíbe la intervención de la autoridad federal y de los Estados federados en materia religiosa, reconoce la plena libertad de los cultos, extingue el padroado y establece otras providencias, como la personalidad jurídica de todas las iglesias y confesiones religiosas. Así, aun considerando los límites socioeconómicos y culturales, la República confiere, al menos en tesis, el inicio del ejercicio de la ciudadanía para los brasileños y brasileñas. El Estado laico es confirmado por la primera Constitución Republicana, en 1891, bien como en la Constitución en vigor, de 1988.

La laicidad del Estado en todos los ámbitos de la vida pública, incluyendo la escuela pública, es condición y garantía de la acogida de la pluralidad, de la diversidad, de la libertad y de la igualdad, contribuyendo para el fortalecimiento de la democracia y el respeto a la dignidad humana.22 "El principio del Estado laico puede ser directamente relacionado a dos derechos fundamentales que gozan de máxima importancia en la escala de los valores constitucionales: libertad de religión e igualdad"23. El Estado, siendo laico, no debe establecer preferencias o manifestarse por medio de sus órganos,

[...] la coexistencia pacífica de las religiones en la esfera pública depende de que sea garantizada, a todas, igual valor del punto de vista público, sin que prevalezca una sobre las otras [...] si un grupo religioso, bajo la alegación de ser mayoritario en dada sociedad, insiste en garantizar la hegemonía para sí, ya sea aisladamente, ya sea en composición con otros grupos, la situación se agrava. Puede ese grupo oscilar del desprecio [...] al odio, en relación a todos los que resisten a esta hegemonía. ${ }^{24}$

22 STRÖHER, 2014, p. 9-15.

${ }^{23}$ SARMENTO, Daniel. Representação ao Procurador-Geral da República. Ministério Público Federal Propositura de Ação Direta de Inconstitucionalidade. In: CONSELHO NACIONAL DO MINISTÉRIO PÚBLICO. Ministério Público em defesa do Estado Laico: Prática Processual, v. 2. Brasília: CNMP, 2014. p. 20.

${ }^{24}$ FISCHMANN, Roseli. Estado Laico. São Paulo: Memorial da América Latina, 2009. p. 9-15. 
Sin embargo, hay una cobranza incisiva por parte de las religiones, muchas de ellas organizadas en bancadas en el Congreso Nacional, de existir actitudes e interferir en decisiones políticas y jurídicas, a fin de que estas sean pautadas por sus respectivos valores religiosos y que no disientan de sus intereses, confundiendo las esferas de público y privado y tomando las nociones de moralismo y pecado como una referencia de gobernabilidad. Un ejemplo de esta interferencia fue el impeachment ${ }^{25}$ de la Presidenta Dilma Vana Rousseff, em 2016, donde el 93\% de los parlamentares evangélicos, bien como la bancada del agronegocio y de los militares electos, votaron por el impedimento aclamando a Dios y los valores de la familia, lo que demuestra que las bases de sus votos eran, en verdad, contrariedad a las políticas públicas en favor de los derechos humanos y la inclusión social.

Roseli Fischmann destaca que no se puede pretender que "el Estado establezca como crimen lo que una confesión religiosa tiene como pecado" 26 , comprometiendo la garantía de los derechos civiles. Christina Vital y Paulo Victor Leite, en la publicación Religión y Política hacen un análisis pertinente sobre la actuación y las presiones de líderes religiosos y la actuación de parlamentares, especialmente evangélicos, en relación a los derechos de las mujeres y de LGBTs, entre otros, mostrando la ambigüedad existente entre lo laico y lo confesional en Brasil ${ }^{27}$. Flávia Piovesan observa con pertinencia esta ambigüedad:

En el Estado laico, marcado por la separación entre el Estado y la religión, todas las religiones merecen igual consideración y profundo respeto, inexistiendo, con todo, cualquier religión oficial, que se transforme en la única concepción estatal a abolir la dinámica de una sociedad abierta, libre, diversa y plural. Existe el deber del Estado en garantizar las condiciones de igualdad religiosa y moral, en un contexto desafiador en que, si de un lado el Estado contemporáneo busca separarse de la religión, esta, por su vez, busca entrar en los dominios del Estado (ejemplo: bancadas religiosas en el Legislativo). ${ }^{28}$

En relación a la intolerancia religiosa, algunas políticas públicas fueron inseridas en el ámbito de la Secretaría de Derechos Humanos de la Presidencia de la República, como la Asesoría Especial para Derechos Humanos y Diversidad Religiosa, la creación del Comité Nacional de Diversidad Religiosa (24 de enero de 2013) y la apertura del "Disque Derechos Humanos" para las denuncias de violaciones por intolerancia religiosa.

${ }^{25}$ Para ampliar ese tema sugerimos: NÚÑEZ DE LA PAZ, Nivia Ivette; BENCKE, Romi Márcia (Orgs.). Presidenta Dilma: en sororidad mujeres rescatan la historia. São Leopoldo: Karywa, 2017.

${ }^{26}$ FISCHMANN, 2009, p. 6.

27 VITAL, Christina; LOPES, Paulo Victor Leite. Religião e Política: uma análise da atuação de parlamentares evangélicos sobre direitos humanos e de LGBTs no Brasil. Rio de Janeiro: Instituto Heinrich Böll; Instituto de Estudos da Religião, 2012. Disponível em: $<$ https://br.boell.org/sites/default/files/publicacao_religiao_e_ politica_chris_vital_e_paulo_victor_14mar_webfinal.pdf $>$. Acesso em: 20 jan. 2020.

28 PIOVESAN, Flávia. Direito Constitucional Módulo V. Direitos Humanos e Direito Constitucional Internacional. In: SCHILLING, Maria Luiza Bernardi Fiori (Org.). Caderno de Direito Constitucional. São Paulo: Escola da Magistratura do Tribunal Regional Federal da $4^{\mathrm{a}}$ Região, 2006. p. 15. Disponível em: $<$ http://www2.trf4.jus. $\mathrm{br} / \mathrm{trf} 4 /$ upload/arquivos/emagis_atividades/ccp5_flavia_piovesan.pdf $>$. Acesso em: $30 \mathrm{jan} .2020$ 


\section{El sistema de protección de la libertad religiosa}

Brasil también tiene asegurada la libertad religiosa en la Constitución y algunos dispositivos legales como leyes y recomendaciones para preservar la libertad religiosa y cohibir la intolerancia religiosa. La Ley $\mathrm{n}^{\circ} 7.716$, de 5 de enero de 1989 (actualizada por la Ley $\mathrm{n}^{\circ}$ 9.459, de 13 de mayo de 1997, adicionando párrafo en el artículo 140 del Decreto-Ley n ${ }^{\circ} 2848$, de 7 de diciembre de 1940), dispone que "serán sancionados, en la forma de esta Ley los crímenes resultantes de discriminación y prejuicio de raza, color, etnia, religión o procedencia nacional".

La Ley $\mathrm{n}^{\circ} 11.635$, de 27 de diciembre de 2007, instituyó el Día Nacional del Combate a la Intolerancia Religiosa. Y el Decreto $\mathrm{n}^{\circ} 7.037$, de 21 de diciembre de 2009 instituyó el Programa Nacional de Derechos Humanos III (PNDH - 3), el cual asegura el "respeto a las diferentes creencias, libertad de culto y garantía de la laicidad del Estado" (Eje 10, Garantía de la igualdad en la diversidad, Objetivo Estratégico VI). Y la Plenaria del Consejo Nacional de Seguridad Pública "recomienda que en los Boletines de Ocurrencia, términos Circunstanciados o similares de los órganos de Seguridad Pública, sea incluido campo o espacio obligatorio donde pueda ser identificado o relacionar el crimen perpetrado o investigado con motivación o connotación de intolerancia religiosa" 29 .

La búsqueda por el respeto a la libertad de religión y de culto y al reconocimiento de la diversidad religiosa a partir de los parámetros de los derechos humanos se convierte en un desafío cotidiano. Y tenemos, además de los dispositivos legales del país, todavía amparo en instrumentos legales internacionales. Específicamente en la Declaración Universal de los Derechos Humanos, en su Artículo XVIII, como ya vimos anteriormente, y en la Convención Americana de Derechos Humanos (1969, Pacto de San José de Costa Rica) que tiene importancia fundamental por formar parte de nuestro ordenamiento jurídico, que fue ratificado por Brasil en 1992, protegiendo de forma explícita e incisiva, en el Artículo 12, la libertad de conciencia y religión.

1. Toda persona tiene derecho a la libertad de conciencia y religión. Ese derecho implica la libertad de conservar su religión o sus creencias. O de cambiar de religión o de creencias, bien como a la libertad de profesar divulgar su religión o sus creencias individual o colectivamente, tanto en público como en privado.

2. Nadie puede ser objeto de medidas restrictivas que puedan limitar su libertad de conservar su religión o sus creencias, o de cambiar de religión o de creencia. ${ }^{30}$

Y la Declaración sobre la Eliminación de todas las Formas de Intolerancia e Discriminación Fundadas en la Religión o Convicción (1981) preconiza en su Artículo 1 que

${ }^{29}$ RECOMENDAÇÃO n ${ }^{\circ}$ 010, de 20 de abril de 2012, Plenária do Conselho Nacional de Segurança Pública (CONASP/MJ).

${ }^{30}$ LEGISLAÇÃO CITADA ANEXADA PELA COORDENAÇÃO DE ESTUDOS LEGISLATIVOS CEDI DECRETO Nº 678, DE 6 DE NOVEMBRO DE 1992. Disponível em: <http://www.tjrr.jus.br/cij/ arquivospdf/ConvencaoAmericana-pacjose-1969.pdf>. Acesso em: 22 jan. 2020. 
$\S 2$. Nadie será objeto de coacción capaz de limitar su libertad de tener una religión o convicciones que haya escogido.

$\S 3$. La libertad de manifestar la propia religión o las propias convicciones estará sujeta únicamente a las limitaciones prescritas en la ley que sean necesarias para proteger la seguridad, el orden, la salud o la moral pública o los derechos y libertades fundamentales de los demás. ${ }^{31}$

La Declaración Universal de la Laicidad en el Siglo XXI, presentada en el seminario francés en ocasión del centenario de la separación estado-Iglesia en Francia, el 9 de diciembre de $2005^{32}$, aun cuando no tiene un carácter legal, es cuando menos, inspiradora. Esta Declaración afirma en su Artículo $1^{\circ}$ que,

Todos los seres humanos tienen derecho al respeto de su libertad de conciencia y a su práctica individual y colectiva. Este respeto implica en la libertad de adherir o no a una religión o a convicciones filosóficas (incluyendo el ateísmo y el agnosticismo), el reconocimiento de la autonomía de la conciencia individual, de la libertad personal de los seres humanos y de su libre decisión en materia de religión y convicción. Eso también implica en el respeto por el Estado, dentro de los límites de un orden público democrático y del respeto a los derechos fundamentales, a la autonomía de las religiones y de las convicciones filosóficas. ${ }^{33}$

En el contexto actual todos estos principios y referenciales de garantías y recomendaciones con relación a la diversidad y libertad religiosa están relativizadas o negadas y ninguna política de respeto a la diversidad religiosa es desarrollada.

La libertad religiosa y la laicidad del Estado están cada vez más distantes de las instituciones y del cotidiano brasileño, tanto por las prácticas y posturas políticas, culturales y religiosas, especialmente por los cristianos de bies neopentecostal. "Las relaciones de la vida cotidiana entre la iglesia y la política van tornando cada vez más difícil enfrentar, de hecho, la construcción del estado Laico, tanto en su formalidad como en su práctica." ${ }^{34}$

El cristianismo se colocó históricamente a lo largo del proceso de colonización y hasta la contemporaneidad como norma socio-cultural e religiosa. Y acabó suprimiendo, irrespetando y ejerciendo la violencia y la intolerancia en relación a las demás religiones que forman la diversidad religiosa del contexto brasileño.

${ }^{31}$ DECLARAÇÃO SOBRE A ELIMINAÇÃO DE TODAS AS FORMAS DE INTOLERÂNCIA E DISCRIMINAÇÃO FUNDADAS NA RELIGIÃO OU NAS CONVICÇÕES. Disponível em: <https://www. oas.org/dil/port/1981Declara.pdf >. Acesso em: 23 jan. 2020.

32 Veja LOREA, Roberto Arriada (Org.). Em defesa das Liberdades laicas. Porto Alegre: Livraria do Advogado, 2008.

33 DECLARAÇÃO UNIVERSAL DA LAICIDADE NO SÉCULO XXI. Disponível em: <http://www. nepp-dh.ufrj.br/ole/disponiveis1.html>. Acesso em: 24 jan. 2020.

${ }^{34}$ ÁVILA, Maria Betania de Melo. Reflexões sobre Laicidade. In: BATISTA, Carla; MAIA, Mônica (Orgs.). Estado laico e liberdades democráticas. Recife: Articulação de Mulheres Brasileiras; Rede Nacional Feminista de Saúde; SOS Corpo - Instituto Feminista para a Democracia, 2006. p. 17. Livro em versão on-line/ PDF. Disponível em: <http://www.aads.org.br/arquivos/EL_2006.pdf>. Acesso em: 20 de jan. 2020. 
Las cuestiones de intolerancia religiosa enfrentadas en el país están ligadas al racismo y a la comprensión equivocada de la laicidad, en que indios y negros no serían la mayoría en esta llamada democracia y, por tanto, deben someterse a las injerencias y al metadiscurso religioso normativo y ni recibir cualquier privilegio de la religión de las mayorías. Es la perpetuación de la colonialidad bajo los auspicios de un discurso democrático. Este proceso de disminución genera intolerancia e irrespeto porque no hay reconocimiento del otro, del diferente como sujeto de derechos, con saber propio, cultura:

El intento de destrucción de la diversidad religiosa es parte del proceso de colonización. [...] La intolerancia a lo que es diverso, desde el punto de vista religioso, es parte de nuestra colonización y esa intolerancia se extendió al campo de la cultura como un todo, creando justamente un conflicto entre las culturas de los diferentes pueblos y la cultura hegemónica del colonizador, totalmente apoyada en el orden religioso como campo de legitimación del poder económico y político. ${ }^{35}$

\section{Brasil por encima de todo, Dios por encima de todos - Cristofascismo}

El slogan del actual gobierno brasileño Brasil por encima de todo, Dios por encima de todos ha sido proclamado en diferentes eventos y conferencias, estableciendo una relación estricta entre política/estado y religión. No se sabe de qué Dios el gobierno Bolsonaro está hablando! Para algunos cristianos, especialmente, relacionados al neopentecostalismo Jair Messias Bolsonaro, el actual presidente es el ícono de un verdadero cristiano para sus electores. Sin embargo, un gran grupo de cristianos y cristianas se pregunta como un cristiano quiere gobernar haciendo el gesto "arma" con su mano, defendiendo el militarismo y la tortura, y apelando al escarnio en relación a las mujeres y a las poblaciones negras e indígenas. La expresión por encima de todo y de todos denota arrogancia y no servicio ${ }^{36}$.

Ya en la campaña presidencial este sujeto dejaba bien clara su línea de pensamiento y acción, casi todo era "hecho en nombre de Dios". Muchos religiosos lo siguieron en el discurso. Fotos con personas y grupos haciendo la señal del arma con las manos dentro de las iglesias y en las manifestaciones de odio contra LGBT, mujeres y negros fue algo que vino, con cierta naturalidad a seguir. El tiene "mesías" en su nombre, entonces ese hecho también es usado para sugerir que él es enviado para combatir el comunismo, el marxismo cultural y la diversidad.

En el tiempo de la campaña electoral, en 2018, muchas iglesias entraron en el discurso pro-bolsonaro que predicaba que "bandido bueno era bandido muerto" y la

35 ÁVILA, 2006, p. 17.

${ }^{36}$ PUTTI, Alexandre. "Deus acima de todos é expressão fascista que esconde sede de poder." Entrevista com o pastor Henrique Vieira. Carta Capital. 30 out. 2019. Disponível em: <https://www.cartacapital.com.br/ diversidade/deus-acima-de-todos-e-expressao-fascista-que-esconde-sede-de-poder/>. Acesso em: 25 jan. 2020. 
liberación de armas para la población ${ }^{37}$. La iglesia cristiana no puede ser un lugar donde se haga señal de armas, necesita ser un lugar de aceptación, de acogida, de solidaridad, de predicación de la paz, de la reconciliación. Por tanto, el discurso del actual presidente brasileño hiere el cristianismo en su esencia y práctica de los derechos humanos.

La teóloga alemana Dorothee Sölle, fallecida en 2003, en la década del 70-80, en su paso por los Estados Unidos como profesora visitante alertaba para un discurso religioso que mezclaba política y religión de grupos cristianos que hacían uso de la televisión para sus predicaciones. ${ }^{38}$ Eran los teleevangelistas, las iglesias electrónicas, que alcanzaban, de manera especial, a las personas empobrecidas y en situación de vulnerabilidad social. Ella reflexionó críticamente sobre esos discursos religiosos y acuñó el concepto de "Christofaschismus", cristofascismo. ${ }^{39}$

Sölle realiza una crítica a la obediencia cristiana ciega a los discursos religiosos fundamentalistas. En este sentido, ella acentúa con su argumento que el papel que la obediencia desempeñaba en el cristianismo fue la base para el fascismo germinar en Alemania en el siglo $\mathrm{XX}^{40}$. A partir de su crítica a la obediencia ciega, ella acuña el concepto Cristofascismo. ¿A que nos estamos refiriendo cuando hablamos de Cristofascismo? A primera vista, el lenguaje que Sölle usa parece ser duro y, talvez, exagerado. No obstante, cuando usa el término "Cristofascismo", ella no estaba necesariamente pretendiendo rotular un líder o un Estado como fascista, por el contrario, lo usa como una advertencia contra el potencial destructivo retratado cuando la religión, la política y la economía trabajan juntas para apoyar el nacionalismo y el capitalismo extremo. En vez de pensar en este término como un rotulo descriptivo, es importante pensar en él como un aviso. El término "Christus fascismus" quiere ser un puntero, que señala apara la alianza entre el cristianismo, el nacionalismo y el capitalismo, y andan de manos dadas con la explotación y la destrucción de la naturaleza, de grupos humanos minoritarios e impone solamente una forma de pensar y vivir. El ensayo sobre Cristofascismo fue escrito por Sölle un tiempo después de ella haber estado enseñando en los EUA y percibir los vínculos entre capitalismo, nacionalismo y la obediencia cristiana en aquel contexto ${ }^{41}$.

La autora reflexiona sobre las predicaciones de Jerry Falwell, un pastor bautista, teleevangelista, conservador, que predicaba la moral cristiana como mayoritaria, en los años de 1980. Sölle critica Falwell y otros por sus discursos religiosos que alcanzaban a los americanos económicamente desfavorecidos, prometiendo "convertir a América en el número uno nuevamente/América para los americanos" y glorificaban

${ }^{37}$ PUTTI, Alexandre. 10 afirmações de Bolsonaro que vão contra o que a Páscoa representa. Carta Capital. 21 abr. 2019. Disponível em: <https://www.cartacapital.com.br/sociedade/10-afirmacoes-de-bolsonaroque-vao-contra-o-que-a-pascoa-representa/>. Acesso em: 20 jan. 2020.

${ }^{38}$ ULRICH, Claudete Beise. Teologia Pública, suas implicações e sua pertinência no Momento Político e Religioso. Palestra realizada em nas Faculdades EST, São Leopoldo/RS, em 12 de setembro de 2018. En esta conferencia, se abordó el concepto de cristofascismo de la teóloga Dorothee Sölle.

39 SÖLLE, Dorothee. Das Fenster der Verwundbarkeit: Theologisch-politische Texte. Stuttgart: Kreuz, 1987.p. 165.

${ }^{40}$ SÖLLE, Dorothee. Fantasia \& Obediência: reflexões para uma ética cristã do futuro. Trad. Enio Paulo Giachini. Petrópolis: Vozes, 1997. p. 18.

${ }^{41}$ SÖLLE, 1987, p. 161-164. 
el libre mercado al tiempo en que simultáneamente solicitaban donaciones significativas de sus miembros ${ }^{42}$.

Sölle capta las palabras de Falwell que caracterizan el uso de los cristianismos para reforzar la ideología y los emprendimientos capitalistas. A seguir presentamos un extracto del discurso de Falwell:

El sistema de libre iniciativa es claramente descrito en la Biblia, en los Proverbios de Salomón. Jesús Cristo deja claro que la ética del trabajo forma parte de su plano para la humanidad. Propiedad privada es bíblica. Concurrencia en los negocios es bíblica. Prácticas comerciales ambiciosas y bien-sucedidas son claramente pre-escritas como parte del plano de Dios para con su pueblo. ${ }^{43}$

En su análisis, Sölle identifica tres elementos-clave que sustentan su concepto de "cristofascismo": 1. La cimentación de la teología cristiana con la ideología capitalista y el nacionalismo (incluyendo la superioridad moral); 2. Una ética del trabajo y 3. Papeles familiares tradicionales que patrullan a las mujeres en particular. Inherentes a esos elementos están las manifestaciones de nacionalismo, militarismo y racismo por parte del liderazgo gubernamental y también entre los cristianos. En ese sistema cristofascista, la prensa libre es ofuscada por la censura y la seguridad nacional se mantiene como doctrina sagrada. Temas de justicia y solidaridad son tratados de manera negligente. ${ }^{44}$

Aspectos similares a los ya reflexionados por Sölle, son presentados por Fabio Py en su artículo Cristofascismo a la brasileña en la elección de 2018, donde señala el espacio en el culto que la Iglesia Bautista dio al actual presidente cuando este se encontraba en la campaña electoral,

Lo más serio aun fue cuando el sacerdote concedió la palabra a Bolsonaro por treinta segundos. En aquel momento el candidato se dijo emocionado y que jamás había pensado en estar en esa posición en que se encontraba. Afirmó: "Yo tengo la paz dentro de mí, y gracias a Dios, yo tengo una familia maravillosa en la figura de mi esposa [...] nosotros tenemos que unir este país, nosotros tenemos que valorizar la familia, hacer con que niños y niñas sean respetados en el aula, debemos barrer el comunismo en Brasil". Encerró su plática con la emblemática frase: "el Estado puede ser laico, más yo soy cristiano". ${ }^{45}$

Por lo tanto, el discurso del actual presidente en la campaña electoral ya dejaba claro que asumía una postura cristiana tradicional y fundamentalista en un Estado laico, afirmando un discurso moralista en favor de la unión del país y de la familia tradicional. Un discurso ideológico donde afirmaba la necesidad de barrer el comu-

42 SÖLLE, 1987, p. 164.

43 SÖLLE, 1987, p. 164.

${ }^{44}$ SÖLLE, 1987, p. 164.

${ }^{45}$ PY, Fábio. Cristofascismo à brasileira na eleição de 2018. Novos Diálogos. 21 set. 2018. Disponível em: $<$ https:// novosdialogos.com/artigos/cristofascismo-a-brasileira-na-eleicao-de-2018/>. Acesso em: 18 jan. 2020. 
nismo, esto significa eliminar lo contradictorio. En su discurso, no aparece ninguna palabra cristiana de acogida, solidaridad, respeto a las diferencias. La iglesia que se dice cristiana fue y continua siendo dispuesta y usada para conjugar el capitalismo, el militarismo y el nacionalismo.

Jesús, que sufrió hambre y pobreza, que practicaba la solidaridad con los oprimidos, prácticamente desaparece de este tipo de discurso religioso. No obstante, es necesario afirmar que Jesús, el Cristo, de los Evangelios nada tiene que ver con el discurso de odio, de violencia, de intolerancia, de muerte que es predicado por ciertos políticos y pastores. La muerte de Jesús en la cruz es el clamor contra todo tipo de violencia. ¿Cómo ser ciudadano/ciudadana y cristiano/cristiana en el tiempo presente, en este país, llamado Brasil, donde los derechos humanos, la libertad de pensar, de expresarse, de practicar o no una religión corren peligro?

\section{Para no concluir... ¿existe un papel de la religión para la democracia y los derechos humanos?}

Hacer una hermenéutica crítica de este proceso de la colonialidad no significa desconsiderar la importancia social y cultural de las religiones y ni aquello que, en un lenguaje teológico específico, se llamaría de actuación "profética" por el papel fundamental que las mismas tuvieron en regímenes de excepción o no democráticos, y en la promoción de diversas acciones sociales que minimizan las carencias y el sufrimiento del pueblo en el proceso de colonización/colonialidad que Brasil pasó. Ellas pueden inclusive, colaborar con el Estado desde que en la forma de la ley y en carácter de colaboración e interés público (Constitución Federal, Artículo 19). Así, la colaboración de la religión es aceptable desde que de interés público y no en la promoción de sus convicciones en particular.

La religión tiene un papel en la propia constitución del espacio público en la medida en que define códigos y valores de ciudadanía. Pero esto no confiere derechos o privilegios a ninguna religión en particular, ni la legitimidad de imponer su sistema religioso como referencia para la administración estatal y la legislación del parlamento en cualquier ámbito.

Aun cuando las religiones puedan contribuir con la fundamentación de determinados valores éticos en el medio público, estos no pueden ser condicionados en la forma de una relativización de los derechos fundamentales y ni condicionar que se condene, en ámbito jurídico y civil lo que para la religión es considerado pecado. Esto no quiere decir que no puedan defender sus dogmas como verdades no universales, y sí como parte de lo privado y circunscrito a su grupo religioso.

Si determinado grupo religioso no concuerda con determinada conducta, nada impedirá que ese grupo recomiende a los que practiquen, en sus vidas privadas, lo que predica 
su doctrina. Igualmente nada le permite o permitirá que pretenda imponer, a todos, esos mismos dictámenes, bajo las formas de la ley. ${ }^{46}$

Lo contrario, o sea, esperar que el Estado y la sociedad tomen para sí un dogma particular, podría ser visto como fundamentalismo, como una forma de interpretar doctrinas de forma absoluta basado por un sistema de verdades hermético y previamente definido, y puede configurarse como fundamentalismo cultural, económico, político y no apenas religioso. Pero el fundamentalismo religioso se extiende al plano cultural y político ${ }^{47}$. No es posible hablar en fundamentalismo religioso sin tener como referencia el conservadurismo político. El fundamentalismo puede ser una amenaza para la democracia. La democracia se establece en la diversidad y el fundamentalismo no convive con la diversidad porque se establece por su propia verdad.

El Estado Democrático de Derecho, que es el caso de Brasil, se legitima y necesita ser regido no por tendencias, valores o normativas religiosas cualquier que ellas sean, y sí por la democracia que se establece por el reconocimiento y puesta en práctica de la diversidad y la inclusión. La laicidad del Estado es una oportunidad de promover la democracia en el país, inclusive la democracia religiosa. Las religiones tienen relevancia social y el potencial de construir a través de su forma de creer, una ética de acción política por la responsabilidad social, colectiva y solidaria, y de colaboración en los procesos de democracia, ciudadanía y garantía de los Derechos Fundamentales.

Esa relevancia social [de las prácticas religiosas], con todo, no está libre de ambigüedades. Por un lado, las prácticas religiosas dan sentido a la vida, al paso que, por otro, justifican visiones opresoras, reclamando así, un espacio más allá de las instituciones religiosas a fin de que la convivencia de los diferentes pueda ser pautada por la crítica a los fundamentalismos y por la búsqueda de identidades abiertas, inclusivas. ${ }^{48}$

Boaventura de Sousa Santos en su libro Si Dios fuese un activista de los Derechos Humanos realiza un levantamiento de las principales teologías progresistas contemporáneas, como la política, la de la liberación, la feminista, etc., y concibe el importante papel de estas en las luchas sociales y en la construcción de derechos humanos y justicia social. Las experiencias religiosas, por medio de ritos, rituales y

${ }^{46}$ FISCHMANN, Roseli. Estado Laico: Direitos a ter direitos. Nossa América. Revista do Memorial da América Latina, n. 26, 2007. p. 12.

${ }^{47}$ BOFF, Leonardo. Fundamentalismo: a globalização e o futuro da humanidade. Rio de Janeiro: Sextante, 2002. Según el autor, fundamentalismo, "Não é uma doutrina. Mas uma forma de interpretar e viver a doutrina. É assumir a letra das doutrinas e normas sem cuidar de seu espírito e de sua inserção no processo sempre cambiante da história, que obriga a contínuas interpretações e atualizações, exatamente para manter sua verdade essencial. Fundamentalismo representa a atitude daquele que confere caráter absoluto ao seu ponto de vista" [No es una doctrina. Es una forma de interpretar y vivir la doctrina. Es asumir la letra de las doctrinas y normas sin cuidar su espíritu y su inserción en el proceso siempre cambiante de la historia, que requiere continuas interpretaciones y actualizaciones, precisamente para mantener su verdad esencial. El fundamentalismo representa la actitud de quien confiere carácter absoluto a su punto de vista]. p. 25.

${ }^{48}$ BOBSIN, Oneide. Fenômeno religioso e metodologias. In: BRANDENBURG, Laude Erandi et al. VI Simpósio de Ensino Religioso: Fenômeno Religioso e metodologias. São Leopoldo: Sinodal; EST, 2009. Contracapa. 
sacramentos, como la eucaristía, el misticismo en el cristianismo, la cábala en el judaísmo, el sufismo en el Islán, la posesión del padre o la madre de santo en la Umbanda o Candomblé (y otras), "genera un sentido intenso de cooperación y presencia que, si fuese colocado a servicio de las luchas de resistencia y liberación de la opresión, podría contribuir para fortalecer y radicalizar la voluntad de transformación social ${ }^{49}$. Santos destaca que las religiones de los oprimidos y las teologías de la liberación "poseen una preciosa experiencia a través de la cual los derechos humanos pueden ganar nuevas voces, nueva vitalidad y nuevas fuerzas ${ }^{50}$.

Flávia Piovesan, considerando la necesidad de garantizar las contradicciones de igual libertad religiosa, llama la atención al hecho de que nos encontramos frente a una realidad, en que grupos religiosos buscan penetrar el Estado justamente cuando este procura separarse de la religión y que es indispensable señalar estrategias de actuación.

Se destacan, aquí, dos estrategias: a) reforzar el principio de la laicidad estatal, con énfasis en la Declaración sobre la Eliminación de todas las formas de Discriminación con base en la Intolerancia Religiosa; y b) fortalecer lecturas e interpretaciones progresistas en el campo religioso, de modo a respetar los derechos humanos. ${ }^{51}$

Por lo tanto, la defensa del Estado Democrático de Derecho incluye la laicidad del estado y el derecho de cada persona a tener o a no tener una religión. En el Estado laico, ninguna tradición religiosa puede sobreponerse a la otra. Es necesario estar en constante alerta sobre las nuevas formas de colonialidad de la vida en su integralidad, a través de discursos cristofascistas. Es necesario denunciar todos los tipos de intolerancia religiosa y garantizar los derechos humanos y la constitucionalidad de la libertad de practicar cualquier religión, desde que la misma no amenace y destruya la vida en su integralidad. La libertad religiosa es un derecho humano que necesita de diálogo y defensa. Afirmamos la necesidad de diálogos que ofrecen el principio de la laicidad, afirmando el derecho a la diversidad religiosa y no permitiendo ningún tipo de intolerancia religiosa. Es necesario fortalecer los estudios, los diálogos, los encuentros entre diferentes tradiciones religiosas, creando una cultura del encuentro, del conocimiento mutuo, del intercambio de saberes y de la construcción de proyectos de sustentabilidad que abriguen el respeto a la diferencia religiosa, erigiendo sociedades democráticas y ciudadanas.

\section{Referencias}

ANTONIAZZI, Alberto et al. Nem anjos nem demônios: interpretações sociológicas do pentecostalismo. Petrópolis: Vozes, 1994.

ÁVILA, Maria Betania de Melo. Reflexões sobre Laicidade. In: BATISTA, Carla; MAIA, Mônica (Orgs.). Estado laico e liberdades democráticas. Recife: Articulação de Mulheres Brasileiras;

${ }^{49}$ SANTOS, Boaventura de Sousa. E se Deus fosse um ativista dos Direitos Humanos. 2. ed. São Paulo: Cortez, 2014. p. 138.

${ }^{50}$ SANTOS, 2014, p. 139.

${ }^{51}$ PIOVESAN, 2006, p. 15-16. 
Rede Nacional Feminista de Saúde; SOS Corpo - Instituto Feminista para a Democracia, 2006. Livro em versão on-line/PDF. Disponível em: <http://www.aads.org.br/arquivos/EL_2006.pdf>. Acesso em: 20 jan. 2020.

BOBSIN, Oneide. Fenômeno religioso e metodologias. In: BRANDENBURG, Laude Erandi et al. VI Simpósio de Ensino Religioso: Fenômeno Religioso e metodologias. São Leopoldo: Sinodal; EST, 2009. Contracapa.

BOFF, Leonardo. Fundamentalismo: a globalização e o futuro da humanidade. Rio de Janeiro: Sextante, 2002.

BORGES, Rosane. In: FERRARI, Mariana. Entrevista com Rosane Borges: O que é necropolítica. E como se aplica à segurança pública no Brasil. Ponte, 25 set. 2019. Disponível em: $<$ https:// ponte.org/o-que-e-necropolitica-e-como-se-aplica-a-seguranca-publica-no-brasil/>. Acesso em: 17 fev. 2020.

BRASIL. Constituição da República Federativa do Brasil. 1988. [recurso eletrônico]. Brasília: Supremo Tribunal Federal, Secretaria de Documentação, 2019. Disponível em: <https://www. stf.jus.br/arquivo/cms/legislacaoConstituicao/anexo/CF.pdf>. Acesso em: 05 fev. 2020.

COSTA, Maria Emilia Corrêa. Apontamentos sobre a liberdade religiosa e a formação do estado laico. In: LOREA, Roberto (Org.). Em defesa das liberdades laicas. Porto Alegre: Livraria do Advogado, 2008. p. 97-116.

CUNHA, Carlos Alberto Motta. Teologia, Direitos Humanos e Pensamento Decolonial. Horizonte, v. 15, n. 47, p. 697-718, jul./set. 2017. Disponível em: $<$ http://periodicos.pucminas.br/index.php/ horizonte/article/view/P.2175-5841.2017v15n47p697>. Acesso em: 05 fev. 2020.

DAMÁZIO, Eloise da Silveira. Descolonialidade e interculturalidade epistemológica dos saberes político-jurídicos: uma análise do pensamento descolonial. Revista Direitos Culturais, n. 6, p. 105-118, 2009. Disponível em: <http://srvapp2s.santoangelo.uri.br/seer/index.php/direitosculturais/article/view/24>. Acesso em: 05 fev. 2020.

DECLARAÇÃO UNIVERSAL DOS DIREITOS HUMANOS. Disponível em: < https://www. unicef.org/brazil/pt/resources_10133.htm>. Acesso em: 05 fev. 2020.

DECLARAÇÃO SOBRE A ELIMINAÇÃO DE TODAS AS FORMAS DE INTOLERÂNCIA E DISCRIMINAÇÃO FUNDADAS NA RELIGIÃO OU NAS CONVICÇÕES. Disponível em: $<$ https://www.oas.org/dil/port/1981Declara.pdf >. Acesso em: 23 jan. 2020.

DECLARAÇÃO UNIVERSAL DA LAICIDADE NO SÉCULO XXI. Disponível em: <http:// www.nepp-dh.ufrj.br/ole/disponiveis1.html>. Acesso em: 24 jan. 2020.

FISCHMANN, Roseli. Estado Laico. São Paulo: Memorial da América Latina, 2009.

FISCHMANN, Roseli. Estado Laico: Direitos a ter direitos. Nossa América. Revista do Memorial da América Latina, n. 26, p. 6-12, 2007.

FRESTON, Paul. Breve histórico do pentecostalismo brasileiro. In: ANTONIAZZI, Alberto et al. Nem anjos nem demônios: interpretações sociológicas do pentecostalismo. Petrópolis: Vozes, 1994. p. 72-159.

GUZMÁN, Boris Alfonso Ramírez. Colonialidade, interculturalidade e educação: desdobramento na relação do povo Mapuche e o Estado do Chile. Dissertação (Mestrado) - Programa de Pós-Graduação em Educação da Universidade Federal de Santa Catarina, Florianópolis, 2011. Disponível em: <https://repositorio.ufsc.br/bitstream/handle/123456789/94931/300059. pdf? sequence $=1>$. Acesso em: 27 de março de 2020.

HUNT, Lynn. A Invenção dos Direitos Humanos: uma história. São Paulo: Companhia das Letras, 2009.

LEGISLAÇÃO CITADA ANEXADA PELA COORDENAÇÃO DE ESTUDOS LEGISLATIVOS - CEDI. Decreto n ${ }^{\circ} 678$, de 06 de novembro de 1992. Disponível em: <http://www. tjrr.jus.br/cij/arquivospdf/ConvencaoAmericana-pacjose-1969.pdf.> Acesso em: 22 jan. 2020. 
LOREA, Roberto Arriada (Org.). Em defesa das Liberdades laicas. Porto Alegre: Livraria do Advogado, 2008.

MARIANO, Ricardo. Neopentecostais: Sociologia do novo pentecostalismo no Brasil. 5. ed. São Paulo: Loyola, 2005.

MBEMBE, Achille. Necropolítica. Arte \& Ensaios, Revista do PPGAV/EBA/UFRJ, n. 32, p. 123-151, dez. 2016. Disponível em: <https:/www.procomum.org/wp-content/uploads/2019/04/ necropolitica.pdf>. Acesso em: 18 fev. 2020.

NÚÑEZ DE LA PAZ, Nivia Ivette; BENCKE, Romi Márcia (Orgs.). Presidenta Dilma: en sororidad mujeres rescatan la historia. São Leopoldo: Karywa, 2017.

PIOVESAN, Flávia. Direito Constitucional Módulo V. Direitos Humanos e Direito Constitucional Internacional. In: SCHILLING, Maria Luiza Bernardi Fiori (Org.). Caderno de Direito Constitucional. São Paulo: Escola da Magistratura do Tribunal Regional Federal da $4^{\text {a }}$ Região, 2006. Disponível em: <http://www2.trf4.jus.br/trf4/upload/arquivos/emagis_atividades/ccp5 flavia_piovesan.pdf $>$. Acesso em: 30 jan. 2020.

PY, Fábio. Cristofascismo à brasileira na eleição de 2018. Novos Diálogos, 21 set. 2018. Disponível em: $<$ https://novosdialogos.com/artigos/cristofascismo-a-brasileira-na-eleicao-de-2018/>. Acesso em: 18 jan. 2020.

PUTTI, Alexandre. "Deus acima de todos é expressão fascista que esconde sede de poder." Entrevista com o pastor Henrique Vieira. Carta Capital, 30 out. 2019. Disponível em: $<$ https:// www.cartacapital.com.br/diversidade/deus-acima-de-todos-e-expressao-fascista-que-escondesede-de-poder/>. Acesso em: 25 jan. 2020.

PUTTI, Alexandre. 10 afirmações de Bolsonaro que vão contra o que a Páscoa representa. Carta Capital, 21 abr. 2019. Disponível em: $<$ https://www.cartacapital.com.br/sociedade/10-afirmacoesde-bolsonaro-que-vao-contra-o-que-a-pascoa-representa/>. Acesso em: 20 jan. 2020.

QUIJANO, Aníbal. Colonialidade do poder e classificação social. In: SANTOS, Boaventura de Sousa; MENESES, Maria Paula (Orgs.). Epistemologias do Sul. São Paulo: Cortez, 2010. p. 73-117.

RECOMENDAÇÃO nº 010, de 20 de abril de 2012, Plenária do Conselho Nacional de Segurança Pública (CONASP/MJ).

SANTOS, Boaventura de Sousa. E se Deus fosse um ativista dos Direitos Humanos. 2. ed. São Paulo: Cortez, 2014.

SANTOS, Boaventura de Sousa; MENESES, Maria Paula (Orgs.). Epistemologias do Sul. São Paulo: Cortez, 2010.

SARMENTO, Daniel. Representação ao Procurador-Geral da República. Ministério Público Federal Propositura de Ação Direta de Inconstitucionalidade. In: CONSELHO NACIONAL DO MINISTÉRIO PÚBLICO. Ministério Público em defesa do Estado Laico: Prática Processual, v. 2. Brasília: CNMP, 2014. p. 12-29.

SÖLLE, Dorothee. Das Fenster der Verwundbarkeit: Theologisch-politische Texte. Stuttgart: Kreuz, 1987. p. 158-167.

SÖLLE, Dorothee. Fantasia \& Obediência: reflexões para uma ética cristã do futuro. Trad. Enio Paulo Giachini. Petrópolis: Vozes, 1997.

STRÖHER, Marga Janete. Laicidade e democracia na interface com a laicidade e os direitos humanos. Monografia (Especialização em Gestão de Políticas Públicas em Direitos Humanos) - Escola Nacional de Administração Pública, Brasília, 2014.

TREVISAN, Daniel. Bolsonaro, o gesto da arma na Marcha para Jesus e a risada cafajeste dos pastores. Diario do Centro do Mundo. 22 de junho de 2019. Disponível em: <https://www. diariodocentrodomundo.com.br/bolsonaro-o-gesto-da-arma-na-marcha-para-jesus-e-a-risadacafajeste-dos-pastores-por-daniel-trevisan/>. Acesso em: 20 jan. 2020. 
ULRICH, Claudete Beise. Teologia Pública, suas implicações e sua pertinência no Momento Político e Religioso. Palestra realizada na Faculdades EST, São Leopoldo/RS, 12 de setembro de 2018.

VITAL, Christina; LOPES, Paulo Victor Leite. Religião e Política: uma análise da atuação de parlamentares evangélicos sobre direitos humanos e de LGBTs no Brasil. Rio de Janeiro: Instituto Heinrich Böll; Instituto de Estudos da Religião, 2012. Disponível em: < https://br.boell.org/ sites/default/files/publicacao_religiao_e_politica_chris_vital_e_paulo_victor_14mar_webfinal. pdf>. Acesso em: 20 jan. 2020. 